\title{
Forcing the issue
}

\author{
The candidates in the forthcoming US presidential election have set out their opinions on scientific \\ issues - but in the shadow of possible swingeing cuts in the science budget.
}

The 2012 US presidential election is now in full swing, ahead of polling day on 6 November. The state of the economy looms large among election issues: has incumbent president Barack Obama brought about the change he promised in 2008; although, in the dire economic climate of the last four years, could he? As the American electorate prepares to deliver its verdict on the Obama years, Republican challenger Mitt Romney is proposing a different economic path - of cuts in taxes and government spending, but increased defence spending - in marked opposition to that of Obama.

Amid the economic woes, it's not easy to get other issues onto the table for proper debate by the presidential candidates. But the lobbying organization Science Debate has at least succeeded in getting a statement of some form of science policy from each side, as answers to a set of 14 selected questions. As might be expected, the answers are somewhat light on specifics, and at times betray the hand of staff writers keen to stress the wider political philosophy of their candidate. Nevertheless, they make an interesting read (www.sciencedebate. org/debate12).

Science Debate formed in the run-up to the previous election in 2008 to push for a full presidential debate on science. Although the group claimed the support of some 125 million Americans by election time, both presidential camps refused a televised debate. So Science Debate changed

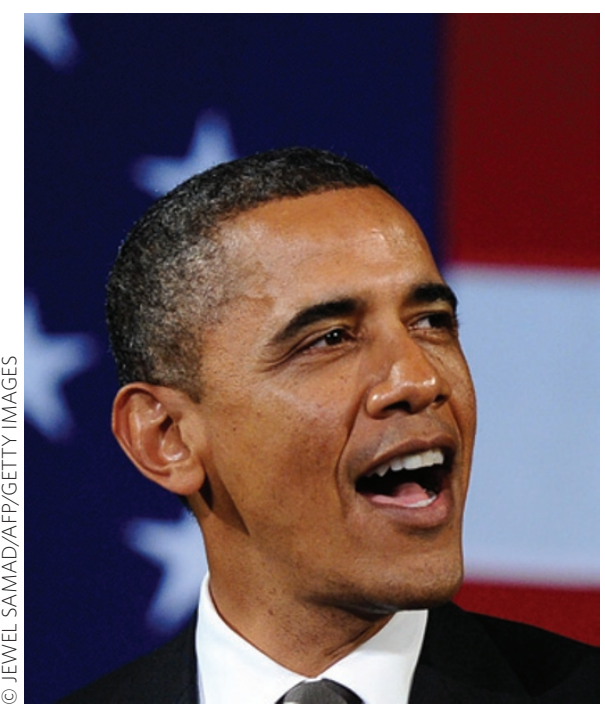

tack and distilled the proposed debate topics into a set of questions, to which the candidates submitted formal replies. Again in 2012, in conjunction with organizations such as the American Association for the Advancement of Science and the Union of Concerned Scientists, Science Debate have interrogated both parties, on matters including innovation, research, education, space, energy and climate change.

Obama, as incumbent, is able to point to some specific initiatives of his administration - such as instituting "the largest research and development increase in [the] nation's history" under the Recovery Act, and launching a programme to train more teachers of STEM subjects. Romney, too, points to Obama's actions on science with the accusation that "higher spending rarely correlates with better results", and that "the answer to spending constraints is to spend money more wisely". Although Romney acknowledges that the US "has moved forward in astonishing ways thanks to national investment in basic research and advanced technology", often his responses lurch into Republican rhetoric about the free market and the middle class. Romney does, however, talk about international partnership in conjunction with NASA and "the nation's space objectives" - as US astronomers call for the country to rejoin the international collaboration developing the Square Kilometre Array of radio telescopes, to be built across South Africa and Australia (http://go.nature.com/oBaKxk).

But either candidate, whatever their wishlist for US science, may find their hands tied by the repercussions of last year's Budget Control Act, instituted to force a reduction in the federal deficit. As, late last year, a congressional committee failed to find a means of capping that debt, a process was set in motion that will cause a 'sequester' - an automatic, across-the-board cut in spending — to hit on 2 January 2013. Negotiations to avoid the sequester are unlikely to happen until after November's election, leaving only a few weeks to find a resolution.

The White House's Office of Management and Budget has produced a 394-page report describing the extent of the possible cuts across all federal departments. The 8.2\% cut in non-defence spending would hit the National Institutes of Health to the tune of
$\$ 2.5$ billion; the National Science Foundation would lose \$463 million for research and related activities, the Department of Energy \$400 million. NASA would find \$417 million less in its science budget, as well as suffering cuts exceeding \$300 million for both space operations and exploration.

Neither presidential candidate has faced the spectre of the sequester in their responses to Science Debate, and no doubt all parties hope it will be avoided. With finances so uncertain, it is the broader philosophical points made by Obama and Romney in the science debate that carry most weight. On science in public policy, Obama recounts that he "directed the White House Office of Science and Technology Policy to ensure that our policies reflect what science tells us without distortion or manipulation". Romney, however, "will ensure that the best available scientific and technical information guides decision-making., and avoid the manipulation of science for political gain" a more positive attitude that was apparent in the administration of his Republican predecessor George W. Bush, but not quite as strong as Obama's statement. And Romney's leanings are particularly clear when he speaks of a "lack of scientific consensus on the issue" of climate change.

The election will be decided on issues other than science, of course. But the tenacity of Science Debate in forcing science onto the agenda, and just that little bit more into the mind of US voters, is commendable.

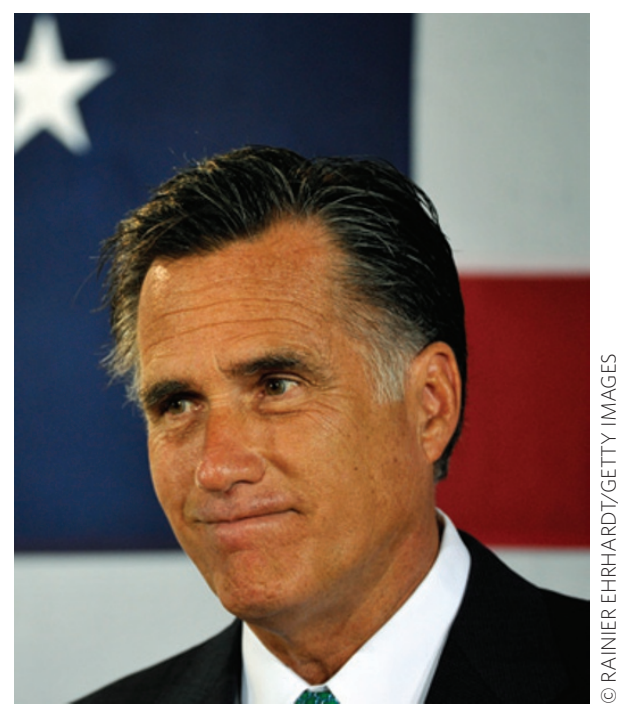

